\title{
Changing oxidoreduction potential to improve water-soluble yellow pigment production with Monascus ruber CGMCC 10910
}

\author{
Tao Huang, Hailing Tan, Fangju Lu, Gong Chen and Zhenqiang Wu*
}

\begin{abstract}
Background: Monascus pigments are widely used in the food and pharmaceutical industries due to their safety to human health. Our previous study found that glucose concentration induced extracellular oxidoreduction potential (ORP) changes could influence extracellular water-soluble yellow pigment production by Monascus ruber CGMCC 10910 in submerged fermentation. In this study, $\mathrm{H}_{2} \mathrm{O}_{2}$ and dithiothreitol (DTT) were used to change the oxidoreduction potential for investigating the effects of oxidative or reductive substances on Monascus yellow pigment production by Monascus ruber CGMCC 10910.

Results: The extracellular ORP could be controlled by $\mathrm{H}_{2} \mathrm{O}_{2}$ and DTT. Both cell growth and extracellular water-soluble yellow pigment production were enhanced under $\mathrm{H}_{2} \mathrm{O}_{2}$-induced oxidative $(\mathrm{HIO})$ conditions and were inhibited under dithiothreitol-induced reductive conditions. By optimizing the amount of $\mathrm{H}_{2} \mathrm{O}_{2}$ added and the timing of the addition, the yield of extracellular water-soluble yellow pigments significantly increased and reached a maximum of $209 \mathrm{AU}$, when $10 \mathrm{mM} \mathrm{H}_{2} \mathrm{O}_{2}$ was added on the 3rd day of fermentation with M. ruber CGMCC 10910. Under HIO conditions, the ratio of NADH/NAD + was much lower than that in the control group, and the expression levels of relative pigment biosynthesis genes were up-regulated; moreover, the activity of glucose-6-phosphate dehydrogenase (G6PDH) was increased while 6-phosphofructokinase (PFK) activity was inhibited.
\end{abstract}

Conclusions: Oxidative conditions induced by $\mathrm{H}_{2} \mathrm{O}_{2}$ increased water-soluble yellow pigment accumulation via up-regulation of the expression levels of relative genes and by increasing the precursors of pigment biosynthesis through redirection of metabolic flux. In contrast, reductive conditions induced by dithiothreitol inhibited yellow pigment accumulation. This experiment provides a potential strategy for improving the production of Monascus yellow pigments.

Keywords: Water-soluble Monascus yellow pigments, Oxidoreduction potential, NADH/NAD+, Enzyme activity, Pigment biosynthesis genes

\section{Background}

Monascus pigments are mixed pigments with three main colours: yellow, orange and red [1]. Recently, Monascus yellow pigments have been widely researched due to their anti-tumour [2, 3], anti-inflammation [4], anti-obesity [5], anti-diabetic, and anti-oxidative stress capabilities [6], and their ability to improving memory and learning

\section{*Correspondence: btzhqwu@scut.edu.cn}

School of Biology and Biological Engineering, Guangdong Provincial Key Laboratory of Fermentation and Enzyme Engineering, South China University of Technology, Guangzhou 510006, China ability [7], counteract metabolic syndromes [8], and treat liver fibrosis [9]. A large body of evidence indicates that Monascus yellow pigments are beneficial to human health in appropriate doses and can potentially be used as nutraceutical or therapeutic agents.

In submerged fermentation, Monascus yellow pigments generally consist of a large amount of intracellular alcohol-soluble pigments and a small amount of extracellular water-soluble pigments [10]. Water-soluble yellow pigments have been a popular area of research due to their high stability and convenient utilization [11]. 
Water-soluble yellow pigments can be synthesized via chemical modification of intracellular alcohol-soluble pigments [12], but this strategy is a potential risk in food applications. In recent decades, considerable effort has been focused on enhancing water-soluble yellow pigment production, such as strain screening $[13,14]$, strain mutation [15], gene modification [16], and medium optimization $[17,18]$. Chen has shown that both extracellular and intracellular yellow pigments are the main pigments produced during long periods of high cell density culturing by Monascus anka [19]. In addition, our previous studies found that extracellular water-soluble yellow pigments can be produced by M. ruber CGMCC 10910 using high glucose concentrations with low oxidoreduction potential (ORP) [20, 21]. However, the pigment yield and glucose utilization was still low.

Oxidoreduction potential was identified as a control parameter for fermentation processes [22-24]. Intracellular ORP is primarily determined by the ratio of NADH/ NAD + [25]. High NADH/NAD+ ratios can regulate intracellular metabolites to generate unusable byproducts, such as alcohol and lactate [26]. However, intracellular ORP can be influenced by changing extracellular ORP [24], while extracellular ORP can be changed by adding oxidative or reductive substances, such as $\mathrm{H}_{2} \mathrm{O}_{2}$, dithiothreitol (DTT), and potassium ferricyanide [24, 27]. It has been reported that spinosad and pseudoaglycone yields increased 3.11-fold in Saccharopolyspora spinosa fermentation under HIO conditions, and high citric acid productivity could be achieved in Aspergillus niger cultures with defined ORP profiles [22, 28]. Therefore, extracellular ORP provides an alternative parameter for the optimization of metabolic production. Monascus pigment biosynthesis occurs via a polyketide pathway and requires many primary metabolites, such as acetylCoA, malonyl-CoA, and NADPH $[1,31,32]$. The pentose phosphate pathway (PPP), a branch pathway of glycometabolism, was shown to be the primary source of NADPH for polyketide and lipid biosynthesis [29]. Recently, the biosynthetic gene cluster of Monascus pigments in the $M$. purpureus and $M$. ruber genome and the functions of some critical genes involved in the pigment biosynthetic pathway were reported [30, 31]. Both the targeted inactivation of MpPKS5 (the homolog of MpigA in M. ruber) in M. purpureus and the targeted-deletion of MpigA in $M$. ruber resulted in the abolishment of pigment production, confirming that polyketide synthase is involved in pigment biosynthesis [31, 32]. The genes MpFasA2 (the homolog of MpigJ in M. ruber) and MpfasB2 (the homolog of MpigK in M. ruber) respectively encode fatty acid synthase $\alpha$-subunit and fatty acid synthase $\beta$-subunit and supply the medium-chain (C8 and $\mathrm{C} 10)$ fatty acyl moieties for Monascus pigments biosynthetic [31-34].
The product profile of mppA (the homolog of $M p i g C$ in $M$. ruber), $m p p C$ (the homolog of MpigE in $M$. ruber) and $m p p E$ (the homolog of MpigG in M. ruber) mutants of $M$. purpureus substantiate that MppA-mediated $\omega-2$ ketoreduction is a prerequisite for the synthesis of the pyranoquinone bicyclic core of the Monascus pigments and $\mathrm{MppC}$ activity determines the regioselectivity of the spontaneous Knoevenagel condensation. The homolog of MpigD in M. ruber) in M. purpureus gene encodes a trichothecene 3-O-acetyltransferase (AT), which can transfer the medium-chain (C8 and $\mathrm{C} 10)$ fatty acyl group into the polyketide chromophore to complete pigment biosynthesis. The mppD (the homolog of MpigF in $M$. ruber) gene in $M$. purpureus encodes an amine oxidase/esterase. The mppR1 (the homolog of MpigB in $M$. ruber) and $m p p R 2$ (the homolog of MpigI in M. ruber) genes in $M$. purpureus are regulatory genes encode transcription factors for pigments biosynthesis [30, 31, 34-36]. Those reports provide a frame of reference from which to investigate external factors on pigment production at the molecular level.

In this study, $\mathrm{H}_{2} \mathrm{O}_{2}$ was added to the fermentation medium of $M$. ruber CGMCC 10910. Its concentration and addition time were also optimized to improve extracellular water-soluble yellow pigment production. In addition, the effect of the oxidative environment induced by $\mathrm{H}_{2} \mathrm{O}_{2}$ on the extracellular and intracellular ORP, the expression levels of pigment biosynthesis genes, and the activities of key enzymes (PFK and G6PDH) in the glycolysis and pentose phosphate pathway (PPP) were also investigated.

\section{Methods}

\section{Microorganism}

Monascus ruber CGMCC 10910, which was deposited at the China General Microbiological Culture Collection Center (CGMCC), was used in this study, and it was cultivated on a potato dextrose agar (PDA) medium at $30^{\circ} \mathrm{C}$ for 7 days and then stored at $4{ }^{\circ} \mathrm{C}$.

\section{Fermentation conditions}

The seed culture medium contained $2 \%$ glucose, $0.3 \%$ yeast extract, $1 \%$ peptone, $0.4 \% \mathrm{KH}_{2} \mathrm{PO}_{4}, 0.05 \% \mathrm{KCl}$, and $0.001 \% \mathrm{FeSO}_{4} \cdot 7 \mathrm{H}_{2} \mathrm{O}$. The fermentation culture medium contained 15\% glucose, $0.5 \%\left(\mathrm{NH}_{4}\right)_{2} \mathrm{SO}_{4}, 0.5 \% \mathrm{KH}_{2} \mathrm{PO}_{4}$, $0.05 \% \mathrm{MgSO}_{4} \cdot 7 \mathrm{H}_{2} \mathrm{O}, 0.05 \% \mathrm{KCl}, 0.003 \% \mathrm{MnSO}_{4} \cdot \mathrm{H}_{2} \mathrm{O}$, $0.001 \% \mathrm{ZnSO}_{4} \cdot 7 \mathrm{H}_{2} \mathrm{O}$, and $0.001 \% \mathrm{FeSO}_{4} \cdot 7 \mathrm{H}_{2} \mathrm{O}$. For the seed culture, 5-6 loopfuls of single colonies (approximately $10 \mathrm{~mm}$ diameter) were scraped off an agar plate and inoculated into a $250 \mathrm{~mL}$ Erlenmeyer flask containing $50 \mathrm{~mL}$ of seed culture medium and agitated at $180 \mathrm{rpm}$ at $30{ }^{\circ} \mathrm{C}$. After $25 \mathrm{~h}, 2 \mathrm{~mL}$ of seed culture was used to inoculate a $250 \mathrm{~mL}$ Erlenmeyer flask containing $25 \mathrm{~mL}$ of 
fermentation culture medium, which was then fermented for 12 days with an agitation speed of $180 \mathrm{rpm}$ at $30{ }^{\circ} \mathrm{C}$. Three duplicates were carried out for each condition.

\section{Addition method of $\mathrm{H}_{2} \mathrm{O}_{2}$ and dithiothreitol (DTT)}

$\mathrm{H}_{2} \mathrm{O}_{2}$ and DTT were filter-sterilized before being added to the medium. One, $5,10,15$ or $20 \mathrm{mM} \mathrm{H}_{2} \mathrm{O}_{2}$ was added to the medium on day 2 of fermentation to study the effect of $\mathrm{H}_{2} \mathrm{O}_{2}$ concentration on cell growth and yellow pigment production. Ten millimolar $\mathrm{H}_{2} \mathrm{O}_{2}$ was added to the medium on day $0,1,3$, and 5 of fermentation to study the effect of $\mathrm{H}_{2} \mathrm{O}_{2}$ addition time on cell growth and yellow pigment production. Three gram per liter DTT was added to the medium on day 3 to study the extracellular reducing conditions on cell growth and yellow pigment production.

\section{Determination of glucose concentration, extracellular oxidoreduction potential (ORP), and DCW}

After being cultured, the fermentation broth was vacuum-filtered through a $0.8 \mathrm{~mm}$ mixed cellulose esters membrane. The filtrate (extracellular broth) was appropriately diluted to determine the residual glucose concentration using the standard 3,5-dinitrosalicylic acid (DNS) method. Extracellular ORP was detected via an oxidation-reduction electrode (Leici, Shanghai) [20]. After filtration, the mycelia were washed 3 times with distilled water and dried at $60{ }^{\circ} \mathrm{C}$ in an oven for $12 \mathrm{~h}$, until a constant mycelia weight was reached to determinate dry cell weight $(\mathrm{DCW})$ by gravity.

\section{Pigment analysis using UV-visible spectrophotometer}

The filtrate (extracellular broth) was appropriately diluted to determine the extracellular water-soluble yellow pigment concentration. The absorbance spectrum of the water-soluble yellow pigments was recorded by a UVvisible spectrophotometer (Unico, USA) from 300 to $550 \mathrm{~nm}$ at $1 \mathrm{~nm}$ intervals, and the absorbance units (AU) at the peak wavelength of $350 \mathrm{~nm}$ was multiplied by the dilution ratio, which was used as an index for the watersoluble yellow pigment concentration [20].

The intracellular pigment concentration was determined according to the following the procedure: the harvested and washed mycelia were resuspended in $25 \mathrm{~mL}$ acidic aqueous ethanol $(70 \% \mathrm{v} / \mathrm{v}, \mathrm{pH}=2$ with hydrochloric acid) and incubated for $1 \mathrm{~h}$. The suspension was filtered with filter paper, and the filtrate (intracellular extract) was appropriately diluted to determine intracellular pigment concentration. The absorbance spectrum of the intracellular pigments was recorded by a UV-visible spectrophotometer (Unico, USA) from 300 to $550 \mathrm{~nm}$ at $1 \mathrm{~nm}$ intervals, and the AU at the peak wavelength of $410 \mathrm{~nm}$ were multiplied by the dilution ratio, which was used as an index for the intracellular yellow pigment concentration.

\section{Analyses of pigment compositions by HPLC}

Analyses of pigment compositions were performed using an Alliance e2695 HPLC system (Waters, Milford, CT, USA) equipped with a 2998 Photodiode Array (PDA) detector (Waters, Milford, CT, USA) and a Zorbax Eclipse Plus C18 column $(250 \times 4.6 \mathrm{~mm}, 5 \mu \mathrm{m}$, Agilent, Palo Alto, CA, USA). The temperature of the column oven was set at $30{ }^{\circ} \mathrm{C}$. A mixture of $\mathrm{H}_{3} \mathrm{PO}_{4}$ solution ( $\mathrm{pH}$ 2.5 , phase $\mathrm{A}$ ) and acetonitrile (phase $\mathrm{B}$ ) were used as the mobile phase using the following gradient program: 0 min, $80 \%$ A, 20\% B; 25 min, 20\% A, $80 \%$ B; 35 min, 20\% A, $80 \%$ B; 36 min, $80 \%$ A, 20\% B; 41 min, 80\% A, 20\% B. The PDA was set at $200-600 \mathrm{~nm}$, and the flow rate of the mobile phase was $0.8 \mathrm{~mL} / \mathrm{min}$ [21].

\section{Determination of the pigment composition using LC-MS}

LC-MS (liquid chromatography-mass spectrometry) consisted of a HP1100 HPLC system (Agilent, Palo Alto, CA, USA) and a microTOF-QII mass spectrometer (Bruker, Rheinstetten, Germany). The C18 column and chromatographic conditions were the same as mentioned above, except for mobile phase A (water, $0.1 \%$ formic acid).

\section{NADH and NAD+ determination}

The intracellular $\mathrm{NADH}$ and $\mathrm{NAD}+$ concentrations were determined using procedures described in previous studies [25, 37]. Mycelia were rapidly ground into a powder using liquid nitrogen; $0.1 \mathrm{~g}$ of mycelia powder was quickly transferred into a sample tube containing $1 \mathrm{~mL}$ of acidic extracting solution $(0.2 \mathrm{M} \mathrm{HCl}$ for $\mathrm{NAD}+)$ or alkaline extracting solution $(0.4 \mathrm{M} \mathrm{KOH}$ for $\mathrm{NADH})$. Next, the samples were heated at $50{ }^{\circ} \mathrm{C}$ for $10 \mathrm{~min}$ and then centrifuged at $12,000 \mathrm{~g}, 4^{\circ} \mathrm{C}$ for $10 \mathrm{~min}$. The supernatant transformed into a tube and was neutralized using alkaline extracting solution or acidic extracting solution. After neutralization, the samples were centrifuged at $12,000 g, 4{ }^{\circ} \mathrm{C}$ for $10 \mathrm{~min}$. The supernatant was collected for NAD+ and NADH determination using the Coenzyme I NAD $(\mathrm{H})$ content test kit (Nanjing Jiancheng Bioengineering Institute, Nanjing, China) according to the manufacturer's instructions. The kit is based on an enzymatic cycling assay method.

\section{Determination of PFK and G6PDH enzyme activities}

Mycelia were rapidly ground into a powder using liquid nitrogen; $0.1 \mathrm{~g}$ of mycelia powder was quickly transferred into a sample tube containing $1 \mathrm{~mL}$ of crude enzyme extracting solution ( $25 \mathrm{mM}$ Tris- $\mathrm{HCl}(\mathrm{pH}=7.6)$, $\left.10 \mathrm{mM} \mathrm{MgCl}_{2}, 20 \mathrm{mM} \mathrm{NH}_{4} \mathrm{Cl}, 0.5 \mathrm{mM} \mathrm{DTT}\right)$ and then 
fully shocked [38, 39]. The protein concentration was quantified using the standard Bradford method. Activity of 6-phosphofructokinase (PFK) was determined using a PFK test kit (Nanjing Jiancheng Bioengineering Institute, Nanjing, China) according to the manufacturer's instructions. Activity of glucose-6-phosphate dehydrogenase (G6PDH) was analysed as reported with minor modifications [39]. A total of $3 \mathrm{~mL}$ of the reaction mixture containing $600 \mu \mathrm{L}$ of $0.2 \mathrm{M}$ Tris- $\mathrm{HCl}(\mathrm{pH}=8.0), 150 \mu \mathrm{L}$ of $5 \mathrm{mM}$ glucose-6-phosphate, $50 \mu \mathrm{L}$ of $5 \mathrm{mM} \mathrm{NADP}+, 2 \mu \mathrm{L}$ of $\beta$-mercaptoethanol, and $20 \mu \mathrm{L}$ of crude enzyme solution was incubated at $30{ }^{\circ} \mathrm{C}$ for $20 \mathrm{~min}$. The G6PDH activity of each sample was then determined spectrophotometrically by measuring the formation of NADPH at $340 \mathrm{~nm}$.

\section{Gene expression analysis}

The relative expression levels of key genes involved in pigment biosynthesis were analysed using real-time quantitative PCR as described previously [21]. Mycelia were collected for total RNA extraction using the Plant RNA Extraction Kit (TaKaRa MiniBEST). First, cDNA was synthesized using the PrimeScript ${ }^{\mathrm{TM}} \mathrm{RT}$ reagent Kit with gDNA Eraser (TaKaRa) according to the supplier's protocol. Primers for the amplification of MpFasA2, MpFasB2, MpPKS5, mppR1, mppA, mppB, mppC, mppD, mppE, mppR2 (GenBank Accession No. KC148521) and the actin gene (GenBank Accession No. AJ417880) are listed in Additional file 1: Table S1. The actin gene was used as a reference gene. Gene expression was monitored by RT-qPCR using SYBR Premix Ex TaqII (TaKaRa). RTqPCR was performed using a LightCycler 96 (Roche, USA) with the following cycling program: pre-incubation at $95^{\circ} \mathrm{C}$ for $30 \mathrm{~s}$, followed by a two-step amplification $(40$ cycles of denaturation at $95{ }^{\circ} \mathrm{C}$ for $5 \mathrm{~s}$, and annealing at $60{ }^{\circ} \mathrm{C}$ for $30 \mathrm{~s}$ ) and dissociation curve analyses (at $95^{\circ} \mathrm{C}$ for $10 \mathrm{~s}$, annealing at $65^{\circ} \mathrm{C}$ for $60 \mathrm{~s}$, then collection of dissociation curves from 65 to $95^{\circ} \mathrm{C}$, with a final incubation at $97^{\circ} \mathrm{C}$ for $1 \mathrm{~s}$ ).

\section{Statistical analysis}

Each experiment was repeated in triplicate, at minimum. Numerical data are presented as the mean \pm SD. The differences among the various treatments were analysed using one-way ANOVA. All statistical analyses were performed by using SPSS 22.0 software, and $p<0.05$ and $p<0.01$ were considered significant and highly significant, respectively.

\section{Results}

Water-soluble yellow pigment production from different $\mathrm{H}_{2} \mathrm{O}_{2}$ concentrations and adding times

Monascus ruber CGMCC 10910 has the potential to produce extracellular water-soluble yellow pigments with a maximum absorbance wavelength of $350 \mathrm{~nm}$ [20], and the extracellular water-soluble yellow pigments could reach a maximum yield of $147 \mathrm{AU}_{350}$ under high glucose stress fermentation [21]. Further analysis was shown that the extracellular water-soluble yellow pigments mainly contained four kinds of yellow pigments (Additional file 2: Figure S1). The cell growth and pigment production achieved by adding various amounts of $\mathrm{H}_{2} \mathrm{O}_{2}$ to the medium on the 2nd day of $M$. ruber CGMCC 10910 fermentation under high glucose stress are shown in Fig. 1. The results showed that lower amounts of $\mathrm{H}_{2} \mathrm{O}_{2}$ could promote cell growth while higher amounts of $\mathrm{H}_{2} \mathrm{O}_{2}$ had an inhibitory effect on cell growth (Fig. 1a). Extracellular and intracellular pigments were enhanced under certain doses of $\mathrm{H}_{2} \mathrm{O}_{2}$ but were inhibited by high concentrations (Fig. $1 \mathrm{a}-\mathrm{c}$ ). The optimal amount of $\mathrm{H}_{2} \mathrm{O}_{2}$ was found to be $10 \mathrm{mM}$, which had a $19 \%$ increase in dry cell weight (DCW), and a 35 and 26\% increase in extracellular and intracellular yellow pigment yield, respectively. Thus, $10 \mathrm{mM}$ was chosen as the suitable concentration for the addition time experiments.

The optimized concentration, $10 \mathrm{mM} \mathrm{H}_{2} \mathrm{O}_{2}$, was added to the fermentation medium at various growth time points, including at day 0 (beginning of fermentation), the 1st day (early exponential phase), the 3rd day (middle exponential phase), and the 5th day (late exponential phase) during pigment fermentation. Cell growth and pigment production, including intracellular and extracellular yellow pigments, were inhibited when $\mathrm{H}_{2} \mathrm{O}_{2}$ was added at the beginning of fermentation (Fig. 2), and these parameters were marginally increased when $\mathrm{H}_{2} \mathrm{O}_{2}$ was added at the late exponential phase. However, when $\mathrm{H}_{2} \mathrm{O}_{2}$ was added at the middle exponential phase, cell growth and pigment production were much improved. The optimal $\mathrm{H}_{2} \mathrm{O}_{2}$ addition time was on the 3rd day (middle exponential phase), in which extracellular watersoluble yellow pigment yield reached approximately 209 $\mathrm{AU}_{350}, 42 \%$ higher than that of the control (Fig. 2a, b), and intracellular yellow pigments also increased by $35 \%$ and reached a maximum of approximately $236 \mathrm{AU}_{410}$ (Fig. 2c). The UV-visible spectra and mass spectra of intracellular yellow pigments were compared with literature data (Additional file 3: Figure S2) [40, 41], which were identified as the two well-known pigments, monascin and ankaflavin. Monascin was the mainly intracellular yellow pigment based on the HPLC profile (Additional file 4: Figure S3), and the maximum yield of monascin under $\mathrm{HIO}$ conditions was $467.75 \mu \mathrm{g} / \mathrm{mL}$.

\section{Water-soluble yellow pigment production under HIO conditions and DTT-induced reductive conditions}

$\mathrm{H}_{2} \mathrm{O}_{2}$ acting as an electron acceptor could cause an extracellular oxidative condition (higher extracellular ORP), 

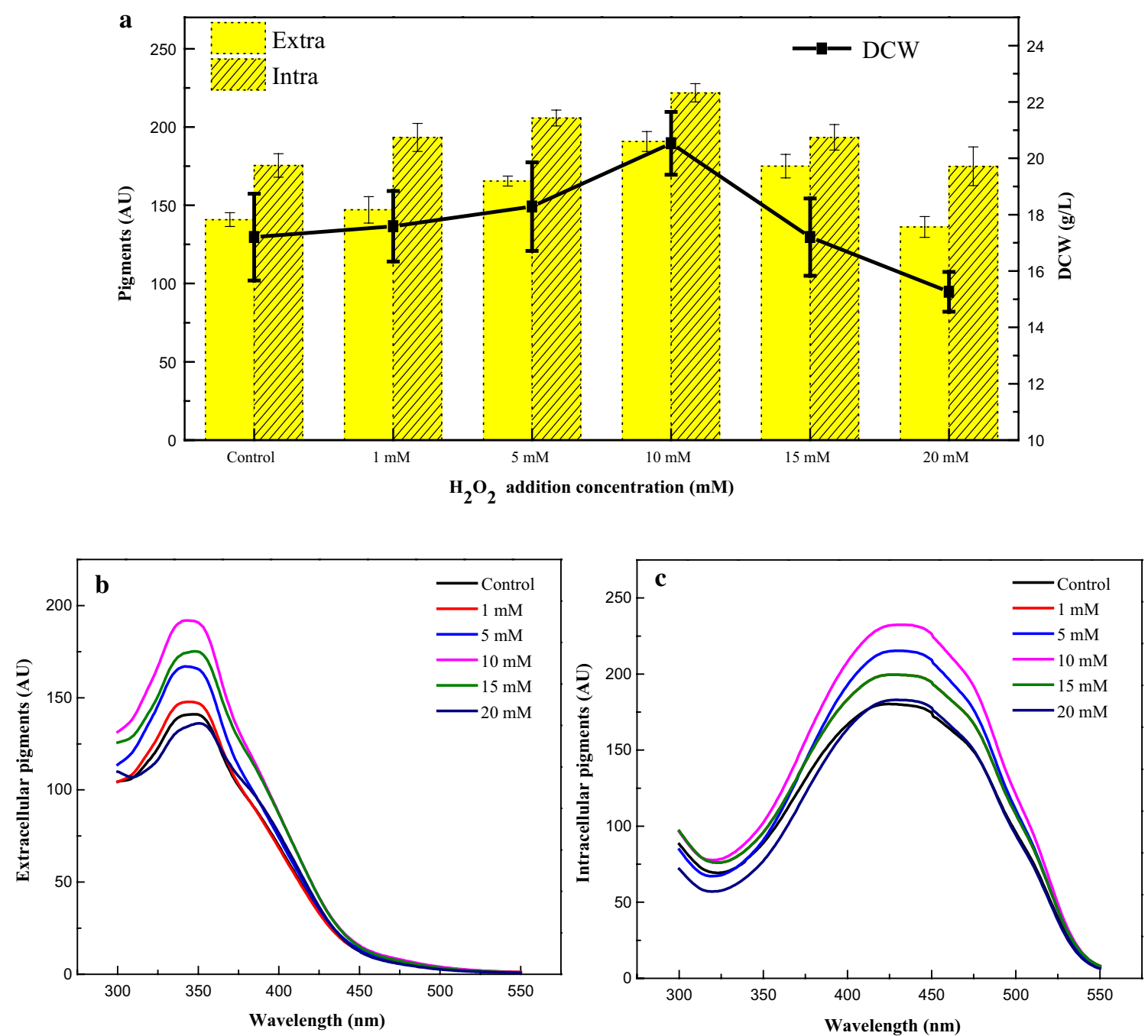

Fig. 1 Pigment production by adding different concentrations of $\mathrm{H}_{2} \mathrm{O}_{2}$ on day 2. a DCW and yield of extracellular and intracellular yellow pigments. b Spectra of extracellular pigments. c Spectra of intracellular pigments

while dithiothreitol (DTT) acting as a reducing agent could reduce the extracellular ORP [24]. $10 \mathrm{mM}$ of $\mathrm{H}_{2} \mathrm{O}_{2}$ was added to the medium on the 3rd day to create an extracellular oxidative environment, and $3 \mathrm{~g} / \mathrm{L}$ DTT was added on the 3rd day to create an extracellular reducing environment. Extracellular ORP increased immediately after $\mathrm{H}_{2} \mathrm{O}_{2}$ addition and reached its highest level on day 4 , then decreased to a low level, similar to the control, in the later phase of the fermentation (Fig. 3a). A low extracellular ORP was also promptly obtained when DTT was added to the medium. The cell growth rate increased under an oxidative environment, which resulted in a $19 \%$ increase in dry cell weight (DCW), while the DCW under a reducing environment increased only slightly by less than $5 \%$ (Fig. $3 \mathrm{~b}$ ). The glucose consumption rate increased immediately upon addition of $\mathrm{H}_{2} \mathrm{O}_{2}$, and the total glucose consumption was higher than that of the control. However, the glucose consumption rate under reducing conditions increased only on day 6 and resulted in the lowest residual glucose concentration (Fig. 3b).

The extracellular water-soluble yellow pigment reaching maximum productivity on day 10 under oxidative conditions and reached $209 \mathrm{AU}_{350}$, which was $42 \%$ higher than that of the control. However, the maximum productivity of the control was reached on day 8. In contrast, the yield of extracellular water-soluble yellow pigments under reducing conditions was significantly decreased (Fig. 3c). Under oxidative conditions, the yield of extracellular water-soluble yellow pigments based on glucose consumption corresponded to approximately 1.45 

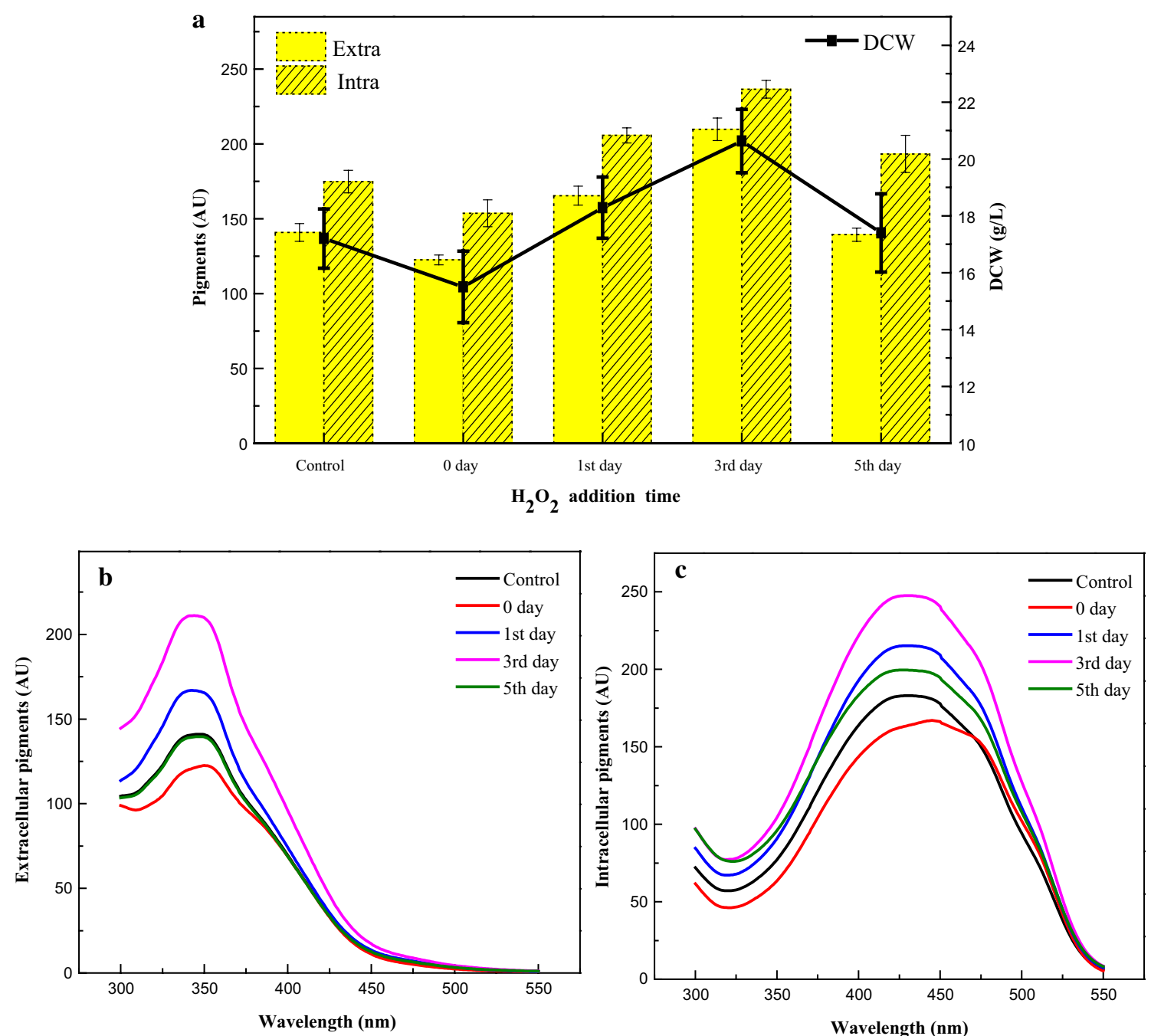

Fig. 2 Pigment production by adding $10 \mathrm{mM} \mathrm{H}_{2} \mathrm{O}_{2}$ at different fermentation times. a DCW and yield of extracellular and intracellular yellow pigments. b Spectra of extracellular pigments. c Spectra of intracellular pigments

$\mathrm{AU} / \mathrm{g}$, which was $37.6 \%$ higher than that of the control. The generation rate of intracellular yellow pigments was increased under oxidative conditions (Fig. 3d). The yield of intracellular yellow pigments under oxidative conditions based on glucose consumption corresponded to approximately $1.54 \mathrm{AU} / \mathrm{g}$, which was $26.4 \%$ higher than that of the control. In contrast, the yield of intracellular yellow pigments under reducing conditions decreased in the later stages of fermentation and resulted in a lower overall yield (Fig. 3d). The yields of extracellular and intracellular yellow pigments per unit DCW under oxidative conditions were higher than that of the control, while those under reducing conditions were lower than the control (Table 1). Which demonstrated that the oxidative conditions improved yellow pigments productivity, while reducing condition played an opposite role. Therefore, extracellular oxidative conditions were better for yellow pigment production.

\section{Intracellular NADH/NAD+ levels under HIO conditions}

As shown in Fig. 4, the ratios of NADH/NAD+ under $\mathrm{HIO}$ and control conditions were increased and reached 1.3 on the 3rd day of fermentation. From the 3rd day to the 6th day, a large amount of energy was needed to transport intracellular nutrients to support the fast growth of mycelia and to biosynthesize metabolic intermediates. Consequently, the formation rate of NADH was less than its consumption rate during the growth stage, which resulted in a sharp decrease of the NADH/ $\mathrm{NAD}+$ ratio during this stage. The decrease rate of the 

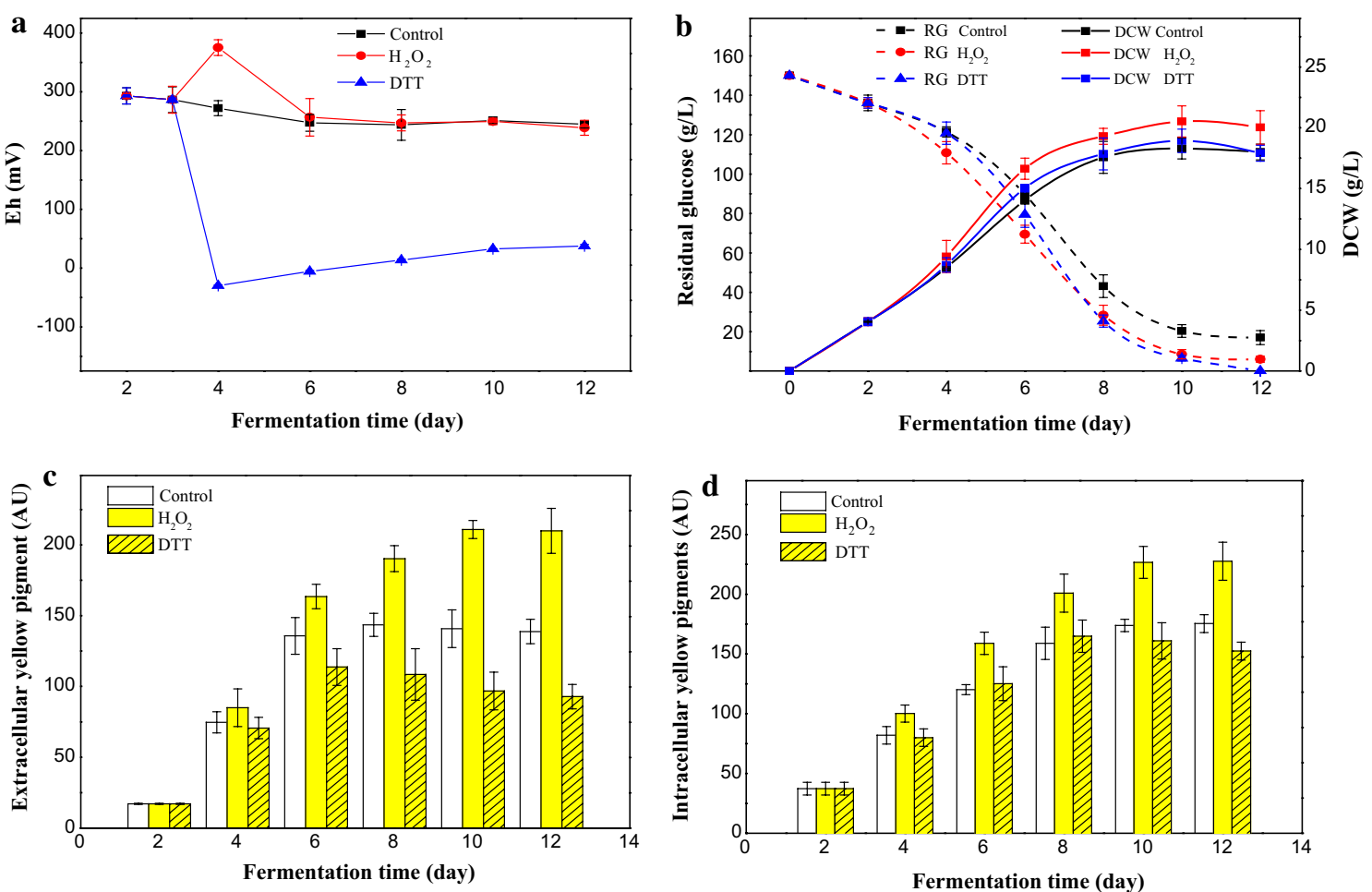

Fig. 3 Pigment production time curve after adding $\mathrm{H}_{2} \mathrm{O}_{2}$ or DTT. a Extracellular ORP. $\mathbf{b}$ Glucose consumption and DCW. RG is the abbreviation for residual glucose. c Extracellular yellow pigments. $\mathbf{d}$ Intracellular yellow pigments

Table 1 Pigments yield per g DCW under HIO conditions and DTT-induced reductive conditions

\begin{tabular}{|c|c|c|c|c|c|c|}
\hline \multirow[t]{2}{*}{ Fermentation time (day) } & \multicolumn{3}{|c|}{ Extracellular yield (AU/g DCW) ${ }^{a}$} & \multicolumn{3}{|c|}{ Intracellular yield (AU/g DCW) } \\
\hline & Control & $\mathrm{H}_{2} \mathrm{O}_{2}$ & DTT & Control & $\mathrm{H}_{2} \mathrm{O}_{2}$ & DTT \\
\hline 0 & - & - & - & - & - & - \\
\hline 2 & $4.21 \pm 0.05$ & $4.21 \pm 0.05$ & $4.21 \pm 0.05$ & $9.21 \pm 0.16$ & $9.21 \pm 0.16$ & $9.21 \pm 0.16$ \\
\hline 4 & $8.77 \pm 0.15$ & $9.03 \pm 0.12 \mathrm{a}$ & $8.11 \pm 0.24 b$ & $9.63 \pm 0.21$ & $9.64 \pm 0.09$ & $9.18 \pm 0.31 a$ \\
\hline 6 & $8.67 \pm 0.09$ & $9.83 \pm 0.29 a$ & $7.56 \pm 0.25 b$ & $8.56 \pm 0.16$ & $9.55 \pm 0.08 a$ & $8.32 \pm 0.29$ \\
\hline 8 & $9.17 \pm 0.34$ & $9.86 \pm 0.16 a$ & $6.08 \pm 0.28 b$ & $9.04 \pm 0.27$ & $10.41 \pm 0.23 a$ & $9.23 \pm 0.41$ \\
\hline 10 & $7.69 \pm 0.16$ & $10.47 \pm 0.12 \mathrm{a}$ & $5.11 \pm 0.34 b$ & $9.50 \pm 0.41$ & $11.04 \pm 0.21 a$ & $8.51 \pm 0.43 b$ \\
\hline 12 & $7.70 \pm 0.04$ & $10.24 \pm 0.08 a$ & $5.18 \pm 0.45 b$ & $9.04 \pm 0.25$ & $11.36 \pm 0.40 a$ & $8.50 \pm 0.18 b$ \\
\hline
\end{tabular}

The values are expressed are means \pm standard deviations, $n=3$ for each treatment

Different letters in row represent statistically different mean values $(p<0.05)$ compared with control

a Extracellular yellow pigments yield per g DCW

b Intracellular yellow pigments yield per g DCW

$\mathrm{NADH} / \mathrm{NAD}+$ ratio under HIO conditions was higher than that of the control and resulted in a lower NADH/ $\mathrm{NAD}+$ ratio in the later exponential phase and stationary phase of the fermentation process. These results indicate that the intracellular oxidoreduction status in $M$. ruber CGMCC 10910 was significantly influenced by $\mathrm{H}_{2} \mathrm{O}_{2}$ addition.

\section{Expression of pigment biosynthesis genes under $\mathrm{HIO}$ conditions}

The pigment biosynthetic gene cluster has been identified in Monascus spp. [31]. The expression of relative pigment biosynthetic genes under $\mathrm{HIO}$ conditions was analysed (Fig. 5). The MpPKS5 gene encodes a pigment polyketide synthase, which is responsible for pigment biosynthesis. MpfasA2 and MpfasB2 encode a fungal 


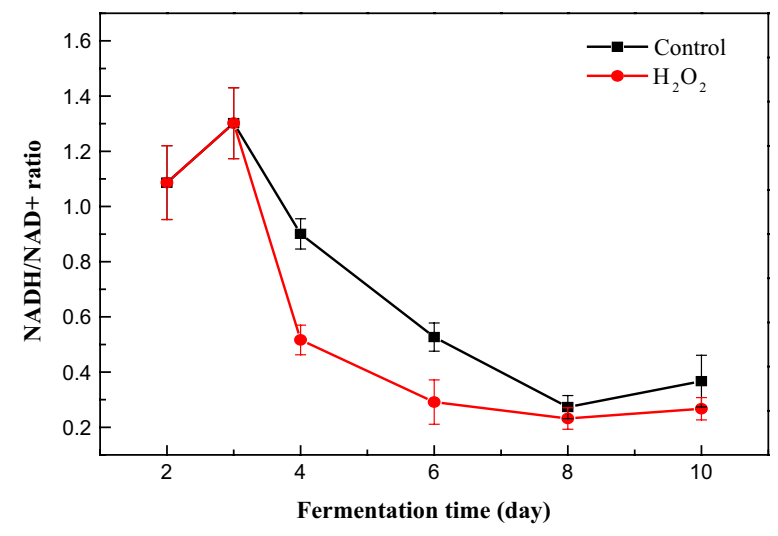

Fig. $4 \mathrm{NADH} / \mathrm{NAD}+$ ratio under $\mathrm{HIO}$ condition fatty acid synthase, which produces medium-chain (C8 and C10) fatty acyl moieties, and then a trichothecene 3-O-acetyltransferase (AT), encoded by the $m p p B$ gene, transfers the medium-chain ( $\mathrm{C} 8$ and $\mathrm{C} 10)$ fatty acyl groups onto the polyketide chromophore to complete pigment biosynthesis. $m p p A, m p p C$, and $m p p E$ encode oxidoreductases, of which a reductive enzyme encoded by $m p p E$ controls the biosynthesis of yellow pigments. The gene $m p p D$ encodes an amine oxidase/esterase. The genes $m p p R 1$ and $m p p R 2$ are regulatory genes for pigment biosynthesis [31, 32].

The expression levels of the genes MpFasA2, MpFasB2, $M p P K S 5, m p p A, m p p B, m p p D, m p p E$, and $m p p R 1$ were significantly up-regulated $(p<0.01$ or $p<0.05)$ under HIO conditions (Fig. 5). This corroborates findings regarding the intracellular and extracellular pigment production under oxidative conditions (Figs. 1, 2), indicating that $\mathrm{H}_{2} \mathrm{O}_{2}$ stimulates pigment production via upregulation of transcript levels of these genes. However, the genes $m p p C$ and $m p p R 2$ were significantly down-regulated $(p<0.01$ or $p<0.05)$ and were negatively correlated with pigment production. It has been reported that $m p p R 2$ is a negative regulatory factor [42].

\section{Variation of PFK and G6PDH activities under HIO conditions}

To understand the physiological consequences of $M$. ruber CGMCC 10910 caused by HIO conditions, the activities of key redox-dependent enzymes (PFK and G6PDH) in glycolysis and the pentose phosphate pathway (PPP) were analysed. As shown in Fig. 6a, PFK activity was inhibited between the 4th day and the 6th day under HIO conditions, which indicated that the glycolysis pathway was weakened when extracellular oxidative conditions were induced by $\mathrm{H}_{2} \mathrm{O}_{2}$. At the same time, G6PDH activity was enhanced between the 4th day and the 8th day under $\mathrm{HIO}$ conditions, which also indicated that the PPP was enhanced under HIO conditions (Fig. 6b). With the metabolic activities weakening, the PFK activity under HIO conditions became equal to that of the control on the 8th day, while G6PDH activity on the 8th day was also higher than that of the control and achieved levels similar to those of the control on the 10th day.

The responses of PFK and G6PDH activities to HIO conditions in this study suggest that there was a metabolic flux redirection from glycolysis to the PPP in $M$. ruber CGMCC 10910 fermentation, similar to that reported by other studies [28, 38, 39]. The higher G6PDH activity under $\mathrm{HIO}$ conditions suggested a higher PPP metabolic reaction rate, thus providing the pigment biosynthesis pathway with ample precursors.

\section{Discussion}

Monascus pigments are mixtures with multiple components $[1,10,43]$. It is difficult to determine the concentration of Monascus pigments with standard HPLC methods. Thus, the concentration of Monascus yellow pigments in this study was represented by the absorbance at their characteristic wavelengths (350 and $410 \mathrm{~nm}$ ) $[20,21]$. In this study, $\mathrm{H}_{2} \mathrm{O}_{2}$ was added at different fermentation time points to study the effects of $\mathrm{H}_{2} \mathrm{O}_{2}$ addition time on cell growth and yellow pigment production in $M$. ruber CGMCC 10910. Cell growth and yellow pigment production were both inhibited when $\mathrm{H}_{2} \mathrm{O}_{2}$ was added at the beginning of fermentation (Fig. 2), indicating the toxic effect of $\mathrm{H}_{2} \mathrm{O}_{2}$ on the conidia germination of $M$. ruber [44]. Cell growth and metabolic activities were slower at the late exponential phase; thus, there was not a significant effect on cell growth and yellow pigment production when $\mathrm{H}_{2} \mathrm{O}_{2}$ was added at this phase. However, extracellular water-soluble yellow pigment production was enhanced by more than $42 \%$, and the DCW increased when $\mathrm{H}_{2} \mathrm{O}_{2}$ was added at the middle exponential phase (Fig. 2), a phase in which cell growth and metabolic activity were robust. The optimal amount of $\mathrm{H}_{2} \mathrm{O}_{2}$ for yellow pigment production was $10 \mathrm{mM}$; lower amounts of $\mathrm{H}_{2} \mathrm{O}_{2}$ were not sufficient to enhance yellow pigment production, while higher amounts of $\mathrm{H}_{2} \mathrm{O}_{2}$ had an inhibitory effect on cell growth and pigment production (Fig. 1). This kind of dose-dependent induction was also observed in other fermentation systems such as Taxus chinensis and Streptomyces hygroscopicus 5008 $[39,45]$. Because the addition of $\mathrm{H}_{2} \mathrm{O}_{2}$ can improve the yield of yellow pigments, additional investigations using the $M$. ruber CGMCC10910 fermentation system were performed.

$\mathrm{H}_{2} \mathrm{O}_{2}$ is an electron acceptor, which can induce an extracellular oxidative environment (higher extracellular ORP) when added to the fermentation medium 


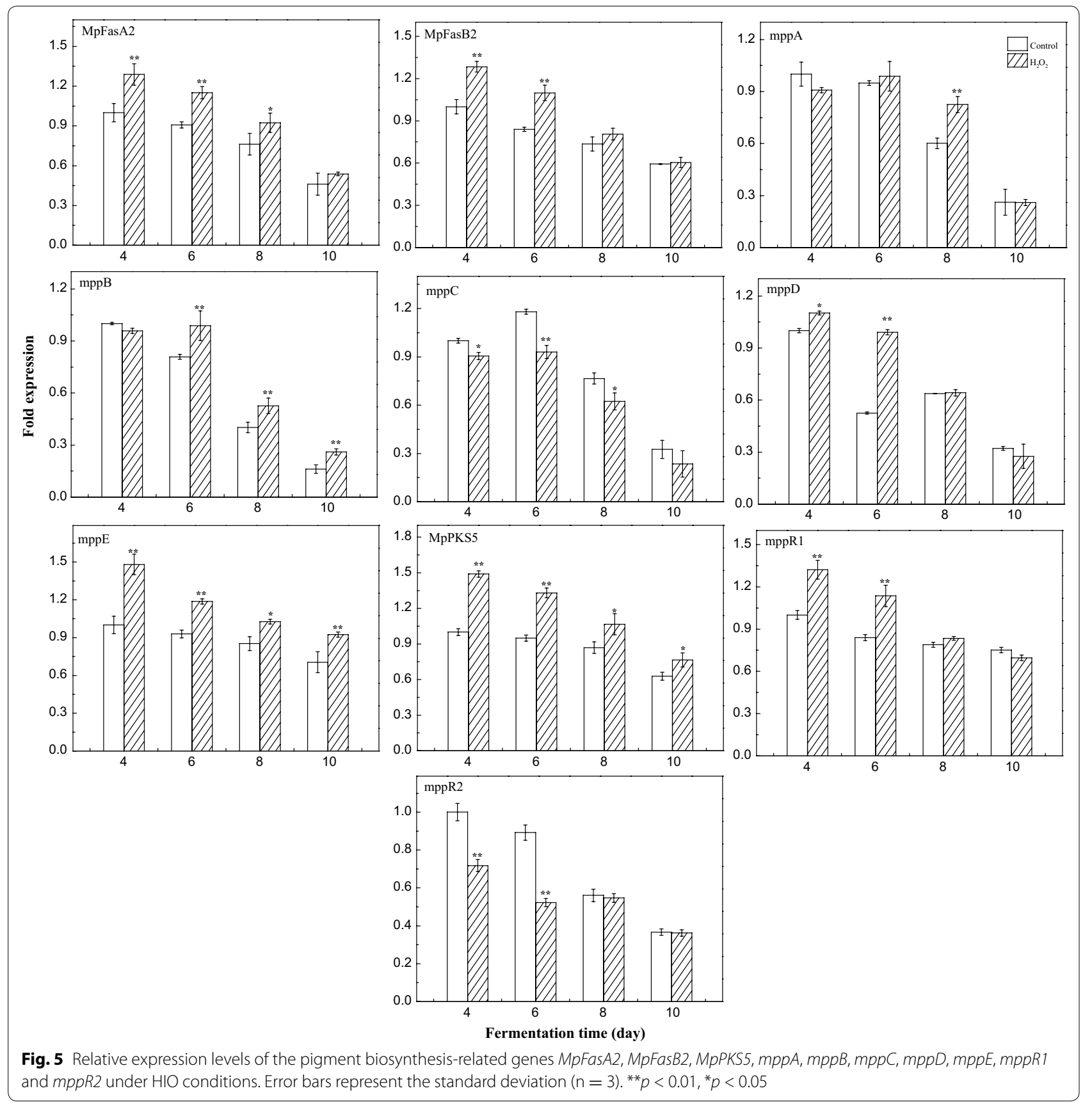

[24]. Meanwhile, DTT acts as a reducing agent and can decrease extracellular ORP, thereby creating reducing conditions in the extracellular environment [46]. In this study, $\mathrm{H}_{2} \mathrm{O}_{2}$ and DTT were used to modify the extracellular ORP to study the effect of extracellular ORP changes on the water-soluble yellow pigment production in $M$. ruber CGMCC 10910. The results showed that the yield of yellow pigments (both extracellular and intracellular) and cell growth under oxidative conditions were significantly increased (Fig. 3b-d), and it has been reported that Monascus pigment production was coupled with cell growth [47]; thus, the HIO condition increased yellow pigment production primarily by enhancing cell growth. In contrast, the reducing environment inhibited the biosynthesis of yellow pigments (Fig. 3), and the yield of intracellular yellow pigments under reducing conditions was decreased in the later phase of fermentation, which resulted in a lower yield. Based on the molecular 

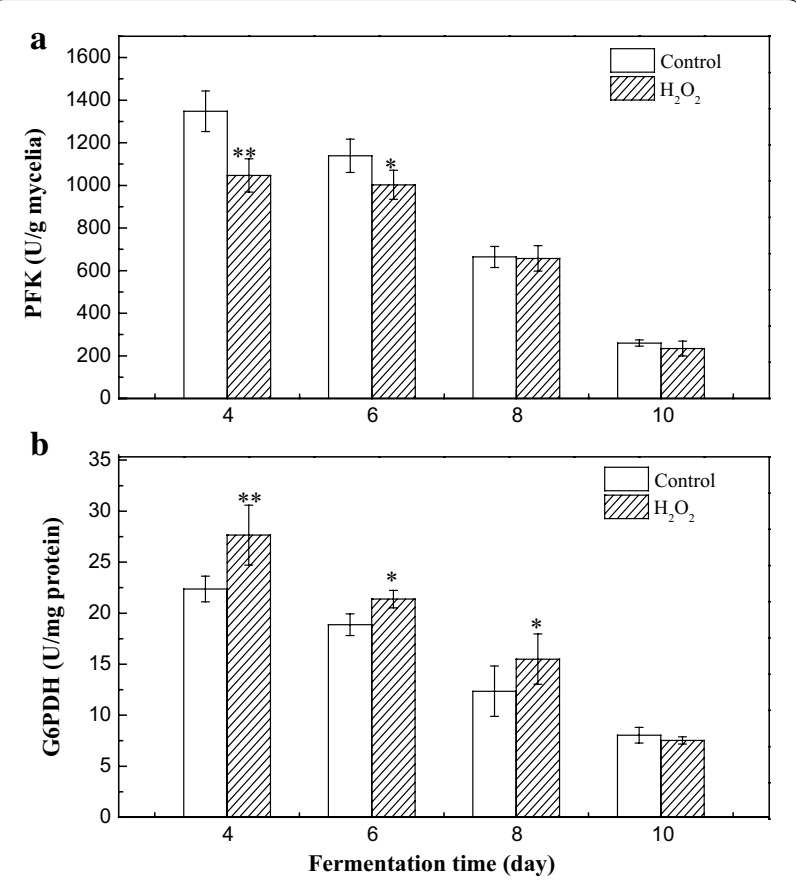

Fig. 6 Activities of PFK and G6PDH under HIO conditions. a PFK activity. b G6PDH activity. ${ }^{*} p<0.05,{ }^{* *} p<0.01$

structure, it is possible that yellow pigments were formed by hydrogenation of orange pigments [43]. Under reducing conditions, the decrease of yellow pigments in the later phase of fermentation could be explained by their transformation into orange pigments. However, the glucose consumption under reducing conditions was enhanced (Fig. 3b), which indicated that there was less flux through the biosynthetic pathway of yellow pigments, and that useless byproducts such as alcohol and lactate were generated [26]. These results indicated that extracellular ORP could influence metabolic flux, which is consistent with reported studies [24, 28, 48].

The intracellular ORP, generally represented by the ratio of NADH/NAD+, has been reported to be influenced by varying the extracellular ORP [24]. In this study, the ratio of NADH/NAD+ in M. ruber CGMCC 10910 was significantly influenced by $\mathrm{H}_{2} \mathrm{O}_{2}$ addition (Fig. 4). During the fermentation process, $\mathrm{H}_{2} \mathrm{O}_{2}$ either accepted electrons from NADH directly, or was degraded to $\mathrm{H}_{2} \mathrm{O}$ and $\mathrm{O}_{2}$. As a result, a portion of $\mathrm{NADH}$ was oxidized to $\mathrm{NAD}+$ by $\mathrm{H}_{2} \mathrm{O}_{2}$ and it achieved a redox balance so that many metabolites, such as NADH dehydrogenases and inefficient terminal oxidases (cytochrome $b d$ ), were not needed to balance NADH/NAD+ metabolism under $\mathrm{HIO}$ conditions [49]. It was speculated that $\mathrm{H}_{2} \mathrm{O}_{2}$ regulating NADH/NAD+ ratios maybe one of the reasons why $\mathrm{DCW}$ and yellow pigment yield were increased under HIO conditions (Fig. 3). During the submerged fermentation of Monascus purpureus, high stirring speed damages the mycelium and results in a lower pigments yield [50]. And the mycelium morphology of Monascus anka plays an important role in polyketides production [51]. Our study found that electron acceptors can be provided by $\mathrm{H}_{2} \mathrm{O}_{2}$ and without increasing stirring speed, which would damage the mycelium morphology of $M$. ruber CGMCC 10910. Moreover, it was reported that yellow pigments are the reduction product of orange pigments [43], in which two of the C-C double bonds in the conjugated chain of two orange pigments are reduced to $\mathrm{C}-\mathrm{C}$ single bonds and reducing power $\mathrm{NADH}$ or $\mathrm{NADPH})$ is required in this reduction reaction [12]. Thus, the ratio of NADH/NAD+ under oxidative conditions was lower than that of the control (Fig. 4).

The biosynthesis of Monascus pigment requires many primary metabolites, such as acetyl-CoA, malonyl-CoA, $\mathrm{NADH}$, and NADPH [52]. NADPH acted as reducing power used for polyketide and lipid biosynthesis [31], which was mainly produced by PPP, which is a branch pathway of glycometabolism [29]. The activities of key enzymes involved in the glycolysis pathway and PPP were analysed in this study. The activity of PFK under HIO conditions was lower than that of the control group (Fig. 6a), which indicates that PFK was allosterically inhibited by higher metabolite concentrations in the glycolysis pathway under HIO conditions [53]. G6PDH activity under oxidative conditions was higher than that of the control group (Fig. 6b), which indicated that the metabolites involved in PPP under oxidative condition were significantly up-regulated. These results showed that $M$. ruber CGMCC 10910 redirects its metabolic flux from the glycolysis pathway to the PPP, and more energy (NADPH) could be produced for polyketide and lipid biosynthesis $[28,35,36]$, which is consistent with reported studies that show that metabolic flux was altered from the glycolysis pathway to the PPP, and an abundance of precursors were available for validamycin A biosynthesis in Streptomyces hygroscopicus 5008 fermentation in response to various oxidant treatments $[38,39]$. Moreover, analysis of the relative expression levels of the pigment biosynthetic genes showed that the genes MpFasA2, MpFasB2, MpPKS5, $m p p A, m p p B, m p p D$, $m p p E$, and $m p p R 1$ were significantly up-regulated under HIO conditions $(p<0.01$ or $p<0.05$ ) (Fig. 5). Thus, HIO conditions increase yellow pigment accumulation via up-regulation of the transcript levels of relative genes and improving the precursor concentrations for pigment biosynthesis.

\section{Conclusions}

Extracellular oxidative conditions caused by $\mathrm{H}_{2} \mathrm{O}_{2}$ addition at suitable fermentation time points can improve the yield of extracellular water-soluble yellow pigments in 
submerged fermentation with M. ruber CGMCC 10910. Cell growth and extracellular water-soluble yellow pigment production of $M$. ruber CGMCC 10910 under $\mathrm{HIO}$ conditions were enhanced, while these parameters were inhibited in reducing conditions induced by dithiothreitol. Intracellular ORP (NADH/NAD+ rates) was decreased by $\mathrm{H}_{2} \mathrm{O}_{2}$ addition; fewer metabolites were used to balance NADH/NAD+, and more energy could thus be directed to cell growth and yellow pigment production instead of unusable metabolite production. The transcription levels of relevant pigment biosynthesis genes were up-regulated under HIO conditions; moreover, the activity of G6PDH was increased while PFK activity was inhibited. HIO conditions increased yellow pigment accumulation via up-regulation of the transcription levels of relevant genes and improving the precursor concentrations of yellow pigment biosynthesis through redirection of metabolic flux, which provides a potential improved strategy for producing water-soluble Monascus yellow pigments.

\section{Additional files}

Additional file 1: Table S1. Primers for RT-qPCR analyzing pigments biosynthetic genes.

Additional file 2: Figure S1. Mass spectra and UV-visible spectra of extracellular yellow pigments detected by LC-MS and HPLC-PDA.

Additional file 3: Figure S2. Mass spectra and UV-visible spectra of intracellular yellow pigment monascin and ankaflavin detected by LC-MS and HPLC-PDA.

Additional file 4: Figure S3. HPLC-PDA chromatogram of intracellular yellow pigments and monascin standard curve detected by HPLC-PDA.

\author{
Abbreviations \\ ORP: oxidoreduction potential; DTT: dithiothreitol; $\mathrm{HIO}: \mathrm{H}_{2} \mathrm{O}_{2}$ induced \\ oxidative; PPP: pentose phosphate pathway; AU: absorbance units; DCW: \\ dry cell weight; PFK: 6-phosphofructokinase; G6PDH: glucose-6-phosphate \\ dehydrogenase.
}

\section{Authors' contributions}

TH planned and carried out the experiments, analysed the data and wrote the manuscript; HLT and FJL assisted in carrying out experiments; GC reviewed the manuscript; ZQW participated in the data analysis and finalized the manuscript. All authors read and approved the final manuscript.

\section{Acknowledgements}

The authors gratefully acknowledge the financial support of the funding.

\section{Competing interests}

The authors declare that they have no competing interests.

\section{Availability of data and materials}

We conducted the experiments and generated the data. All data are shown in figures, tables and additional data.

\section{Consent for publication}

Not applicable.
Ethics approval and consent to participate Not applicable.

\section{Funding}

This study received financial support from the National Natural Science Foundation of China (No: 31271925), the Special Project on the Integration of Industry, Education and Research of Guangdong Province, China (No: 2013B090600015) and the Major Project on synergy innovation in enterpriseuniversity-institute of Guangzhou, China (No: 201604046011).

\section{Publisher's Note}

Springer Nature remains neutral with regard to jurisdictional claims in published maps and institutional affiliations.

Received: 20 August 2017 Accepted: 16 November 2017

Published online: 21 November 2017

\section{References}

1. Patakova P. Monascus secondary metabolites: production and biological activity. J Ind Microbiol Biotechnol. 2013;40(2):169-81.

2. Su NW, Lin YL, Lee MH, Ho CY. Ankaflavin from Monascus-fermented red rice exhibits selective cytotoxic effect and induces cell death on Hep G2 cells. J Agric Food Chem. 2005;53(6):1949-54.

3. Hsu YW, Hsu LC, Liang YH, Kuo YH, Pan TM. Monaphilones A-C, three new antiproliferative azaphilone derivatives from Monascus purpureus NTU 568. J Agric Food Chem. 2010;58(14):8211-6.

4. Hsu L, Liang Y, Hsu Y, Kuo Y, Pan T. Anti-inflammatory properties of yellow and orange pigments from Monascus purpureus NTU568. J Agric Food Chem. 2013:61:2796-802

5. Lee C, Wen J, Hsu Y, Pan T. Monascus-fermented yellow pigments monascin and ankaflavin showed antiobesity effect via the suppression of differentiation and lipogenesis in obese rats fed a high-fat diet. J Agric Food Chem. 2013:61(7):1493-500.

6. Shi Y, Liao VH, Pan T. Monascin from red mold dioscorea as a novel antidiabetic and antioxidative stress agent in rats and Caenorhabditis elegans. Free Radical Biol Med. 2012;52(1):109-17.

7. Lee $C$, Lin P, Hsu Y, Pan T. Monascus-fermented monascin and ankaflavin improve the memory and learning ability in amyloid $\beta$-protein intracerebroventricular-infused rat via the suppression of Alzheimer's disease risk factors. J Funct Foods. 2015:18:387-99.

8. Hsu WH, Pan TM. Treatment of metabolic syndrome with ankaflavin, a secondary metabolite isolated from the edible fungus Monascus spp. Appl Microbiol Biotechnol. 2014;98(11):4853-63.

9. Cheng CF, Pan TM. Ankaflavin and monascin induce apoptosis in activated hepatic stellate cells through suppression of the Akt/NF-kappaB/ p38 signaling pathway. J Agric Food Chem. 2016;64(49):9326-34.

10. Chen $G, W u Z$. Production and biological activities of yellow pigments from Monascus fungi. World J Microbiol Biotechnol. 2016;32:136.

11. Qingqing Z, Di Z, Wenjing T, Chao Y. Photostability of water-soluble and alcohol-soluble Monascus Pigments. Food Sci. 2015;36(1):94-8.

12. Edward J, Paul R, Elaine F. Reduced Monascus pigment derivatives as yellow food colorats. United States patent US 5,013,564. 1991.

13. Barbosa RN, Leong SL, Vinnere-Pettersson O, Chen AJ, Souza-Motta CM, Frisvad JC, Samson RA, Oliveira NT, Houbraken J. Phylogenetic analysis of Monascus and new species from honey, pollen and nests of stingless bees. Stud Mycol. 2017:86:29-51.

14. Jiang Y, Li HB, Chen F, Hyde KD. Production potential of water-soluble Monascus red pigment by a newly isolated Penicillium sp. J Agric Technol. 2005;32:113-26.

15. Zhenqiang W, Gong C, Meihua W. Screening and application of Monascus strains with high yield of extracellular yellow pigment. China Patent No. CN201510449543.6

16. Klinsupa W, Phansiri S, Thongpradis P, Yongsmith B, Pothiratana C. Enhancement of yellow pigment production by intraspecificprotoplast fusion of Monascus spp. yellow mutant (ade-) and whitemutant (prototroph). J Biotechnol. 2016;217:62-71. 
17. Ruijie L, Yumei X, Siqin H, Lei W, Suo C, Mengxiang G, Li L. Optimization of liquid-state fermentation conditions for the production of water soluble yellow Monascus pigment. China Brewing. 2016;35(11):73-7.

18. Shi K, Song D, Chen G, Pistolozzi M, Wu Z, Quan L. Controlling composition and color characteristics of Monascus pigments by $\mathrm{pH}$ and nitrogen sources in submerged fermentation. J Biosci Bioeng. 2015;120(2):145-54.

19. Chen G, Shi K, Song D, Quan L, Wu Z. The pigment characteristics and productivity shifting in high cell density culture of Monascus anka mycelia. BMC Biotechnol. 2015;15:72.

20. Wang M, Huang T, Chen G, Wu Z. Production of water-soluble yellow pigments via high glucose stress fermentation of Monascus ruber CGMCC 10910. Appl Microbiol Biotechnol. 2017;101(8):3121-30.

21. Huang T, Wang M, Shi K, Chen G, Tian X. Metabolism and secretion of yellow pigment under high glucose stress with Monascus ruber. AMB Express. 2017;7(1):79.

22. Berovic M. Scale-up of citric acid fermentation by redox potential control. Biotechnol Bioeng. 1999;64(5):552-7.

23. Du C, Zhang Y, Li Y, Cao ZA. Novel redox potential-based screening strategy for rapid isolation of Klebsiella pneumoniae mutants with enhanced 1,3-propanediol-producing capability. Appl Environ Microb. 2007;73:4515-21.

24. Liu CG, Xue C, Lin YH, Bai FW. Redox potential control and applications in microaerobic and anaerobic fermentations. Biotechnol Adv. 2013;31:257-65.

25. Os-Rivera SJB, Bennett GN, San K. The effect of increasing NADH availability on the redistribution of metabolic fluxes in Escherichia coli chemostat cultures. Metab Eng. 2002;4:230-7.

26. Green J, Paget MP. Bacterial redox sensors. Nat Rev Microbiol. 2004;2:954-66.

27. González-Siso MI, García-Leiro A, Tarrío N, Cerdán ME. Sugar metabolism, redox balance and oxidative stress response in the respiratory yeast Kluyveromyces lacti. Microb Cell Fact. 2009;8:64.

28. Zhang X, Xue C, Zhao F, Li D, Yin J. Suitable extracellular oxidoreduction potential inhibit rex regulation and effect central carbon and energy metabolism in Saccharopolyspora spinosa. Microb Cell Fact. 2014;13:98.

29. Wasylenko TM, Ahn WS, Stephanopoulos G. The oxidative pentose phosphate pathway is the primary source of NADPH for lipid overproduction from glucose in Yarrowia lipolytica. Metab Eng. 2015;30:27-39.

30. Shao Y. Characteristic analysis of transformants in T-DNA mutation library of Monascus ruber. World J Microbiol Biotechnol. 2009;25(6):989-95.

31. Balakrishnan B, Karki S, Chiu S, Kim H, Suh J, Nam B, Yoon Y, Chen C, Kwon H. Genetic localization and in vivo characterization of a Monascus azaphilone pigment biosynthetic gene cluster. Appl Microbiol Biotechnol. 2013;97(14):6337-45.

32. Shao Y, Lei M, Mao Z, Zhou Y, Chen F. Insights into Monascus biology at the genetic level. Appl Microbiol Biotechnol. 2014;98(9):3911-22.

33. Balakrishnan B, Kim H, Suh J, Chen C, Liu K, Park S, Kwon H. Monascus azaphilone pigment biosynthesis employs a dedicated fatty acid synthase for short chain fatty acyl moieties. J Korean Soc Appl Biol Chem. 2014;57(2):191-6.

34. Liu J, Zhou Y, Yi T, Zhao M, Xie N, Lei M, Liu Q, Shao Y, Chen F. Identification and role analysis of an intermediate produced by a polygenic mutant of Monascus pigments cluster in Monascus ruber M7. Appl Microbiol Biotechnol. 2016;100:7037-49.

35. Balakrishnan B, Park S, Kwon H. A reductase gene mppE controls yellow component production in azaphilone polyketide pathway of Monascus. Biotechnol Lett. 2017;39(1):163-9.

36. Balakrishnan B, Suh J, Park S, Kwon H. Delineating Monascus azaphilone pigment biosynthesis: oxidoreductive modifications determine the ring cyclization pattern in azaphilone biosynthesis. RSC ADV. 2014;4(103):59405-8.
37. Wang L, Zhang J, Cao Z, Wang Y, Gao Q. Inhibition of oxidative phosphorylation for enhancing citric acid production by Aspergillus niger. Microb Cell Fact. 2015;14:7.

38. Liao Y, Wei ZH, Bai L, Deng Z, Zhong JJ. Effect of fermentation temperature on validamycin A production by Streptomyces hygroscopicus 5008. J Biotechnol. 2009;142:271-4.

39. Wei Z, Bai L, Deng Z, Zhong J. Enhanced production of validamycin A by $\mathrm{H}_{2} \mathrm{O}_{2}$-induced reactive oxygen speciesin fermentation of Streptomyces hygroscopicus 5008. Bioresour Technol. 2011;102:1783-7.

40. Teng SS, Feldheim W. Analysis of anka pigments by liquid chromatography with diode array detection and tandem mass spectrometry. Chromatographia. 1998;47:529-36.

41. Zheng $Y, X i n Y, G u o$ Y. Study on the fingerprint profile of Monascus products with HPLC-FD, PAD and MS. Food Chem. 2009;113(2):705-11.

42. Chen W, He Y, Zhou Y, Shao Y, Feng Y, Li M, Chen F. Edible filamentous fungi from the species Monascus: early traditional fermentations, modern molecular biology, and future genomics. Compr Rev Food Sci Food Saf. 2015;14:555-67.

43. Juzlova P, Martinkova L, Kren V. Secondary metabolites of the fungus Monascus: a review. J Ind Microbiol. 1996;16:163-70.

44. Shao Y, Li Q, Zhou Y, Chen F. Effects of an alternative oxidase gene on conidia viability under external stresses in Monascus ruber M7. J Basic Microbiol. 2017;9999:1-6.

45. Qian ZG, Zhao ZJ, Tian WH, Xu Y, Zhong JJ. Novel synthetic jasmonates as highly efficient elicitors for taxoid production by suspension cultures of Taxus Chinensis. Biotechnol Bioeng. 2004;5:86.

46. Babu BK, Atiyeh HK, Wilkins MR, Huhnke RL. Effect of the reducing agent dithiothreitol on ethanol and acetic acid production by Clostridium strain P11 using simulated biomass-based syngas. Biol Eng. 2010;3(1):19-35.

47. Vendruscolo F, Schmidell W, De OD, Ninow JL. Kinetic of orange pigment production from Monascus ruber on submerged fermentation. Bioprocess Biosyst Eng. 2016;40:115-21.

48. Riondet $\mathrm{C}$, Cachon R, Waché Y, Alcaraz G, Diviès C. Extracellular oxidoreduction potential modifies carbon and electron flow in Escherichia coli. J Bacteriol. 2000;182(3):620-6.

49. Brekasis D, Paget MS. A novel sensor of NADH/NAD+ redox poise in Streptomyces coelicolor A3. EMBO J. 2003;22(18):4856-65.

50. Jun L, Bobo Z, Gangrong X, Peter CC. Enhanced production of natural yellow pigments from Monascus by liquid culture: a study of the fermentation conditions and mycelial morphology. J Biosci Bioeng. 2017:4(124):452-8.

51. Chen G, Huang T, Bei Q, Tian X, Wu Z. Correlation of pigment production with mycelium morphology in extractive fermentation of Monascus anka GIM 3.592. Process Biochem. 2017:58:42-50.

52. Ruiz B, Chávez A, Forero A, García-Huante Y, Romero A, Sánchez M, Rocha D, Sánchez B, Rodríguez-Sanoja R, Sánchez S, Langley E. Regulationby carbon source. Crit Rev Microbiol. 2010;36(2):146-67.

53. Peng L, Shimizu K. Global metabolic regulation analysis for Escherichia coli K12 based on protein expression by 2-dimensional electrophoresis and enzyme activity measurement. Appl Microbiol Biotechnol. 2003;61(2):163-78.

\section{Submit your next manuscript to BioMed Central and we will help you at every step:}

- We accept pre-submission inquiries

- Our selector tool helps you to find the most relevant journal

- We provide round the clock customer support

- Convenient online submission

- Thorough peer review

- Inclusion in PubMed and all major indexing services

- Maximum visibility for your research

Submit your manuscript at www.biomedcentral.com/submit
BioMed Central 